\title{
On the Relevance of Game Theory in Strategic Thinking
}

\author{
G.N. ENGELBRECHT \\ University of South Africa, Pretoria
}

\begin{abstract}
The author reviews some of the applicable literature and shows how game theory can be used to predict the outcome of a strategy, explain why a particular outcome to a strategy has occurred, investigate strategy and prescribe certain rules for the making of a strategy. $\mathrm{He}$ concludes that game theory can aid decision makers at all levels in formulating quality strategies. In fact, game theory should be an integral and indispensable part of the strategist's toolbox.
\end{abstract}

\section{INTRODUCTION}

Since the beginning of time, man has theorised about the meaning of strategy. Some have said it is an art, others said it is a science. Some thinkers made no pronouncements in this debate, but have given other definitions that have influenced strategic thinking through the ages [6,310]. Sun Tzu, who lived between 400 and 320 BC wrote in his work, The Art of War; "Supreme excellence [in strategy] consists of breaking the enemy's resistance without fighting". Marshal Turenne [1611-1675] defined strategy as; "few sieges and many battles". Napoleon I [1769-1821] declared his preferred strategy to be; "Move upon your enemy in one mass on one line so that when brought to battle, you shall outnumber him and from such a direction that you compromise him".

During the last century Von Clausewitz [12] defined strategy, amongst other things, as the combination of individual engagements to attain the goal of the campaign. He also indicated how strategy should be formulated. He did this with the scientific knowledge available to him at the time. To date, his contribution to the science of strategy remains the single most important dissertation on the subject. It has focused the minds of strategists since then in a particular fashion and much of today's strategy formulation is done against the background that he has purported.

Of course, strategic thinking has also evolved since von Clausewitz's monumental work. This was made possible by the advent of growth in the sciences. Many authors have contributed to the science or art of strategy. For example, in the maritime environment [11, 19-68], the contributions of, amongst others, the Colomb brothers, Alfred T. Mahan, Jeunne Ecole, Sir Julian Corbett, Admiral Sir Herbert Richmond, John Hattendorf and Geoffrey Till have all provided strategic thinking with fresh impetus.

These authors contributed to strategic thinking against the background of scientific knowledge available to them at the time. In particular, the humanities played a significant 
role. As a result, the art or science of formulating strategy has been labelled as being dialectic in nature. Furthermore, in general, the natural sciences were disregarded in the development of strategic thinking. Thus, the development of strategic thinking did not incorporate all the scientific knowledge available to strategic thinkers at that time.

The development of matrix algebra in the previous century facilitated the formulation of a wide variety of new disciplines in the natural sciences. One such discipline is Game Theory which was initiated by Von Neumann and Morgenster [2,1]. Since its inception in the $1920 \mathrm{~s}$, the subject has been the object of serious academic debate. For example, the subject title was considered frivolous and not indicative of the value of the subject within the sciences. Furthermore, many argued that the study of games has no place in the serious business of finding solutions to the problems that beset us. However, if it is possible to define problems and their associated strategies as games, Game Theory can be used to solve such problems.

Also, Binmore $[4,3]$ argued that Game Theory can be used in varying degrees to predict or explain the outcome of a strategy, investigate the causes of a particular outcome to a strategy, describe a particular type of situation with its associated strategies and prescribe optimal strategies. Exactly how this can be achieved in the military and at the national security level is, not widely appreciated.

Therefore, the aim of this paper is to show to what extent game theory is relevant in the study and formulation of strategy. To this end, we will first investigate strategy and then broadly review some general game theory concepts. Thereafter we shall select four specific types of games only, namely, a nonzero-sum game of a non-cooperative nature, a recursive game, a game of exhaustion and an $n$-person game analysed by means of the Shapley value, to investigate to what extent these are relevant to strategic thinking.

\section{STRATEGY}

The elder Von Molkte defined strategy, during the latter part of the last century, as the practical adaptation of the means placed at a general's disposal to the attainment of the object in view; and similarly, in 1954, B.H. Liddel Hart defined strategy as the art of distributing and applying the military means to fulfil the ends of policy $[6,310-311]$.

Likewise, Straffin [10] defines Game Theory as the logical analysis of situations of conflict and co-operation. Engelbrecht $[2,2]$ remarks that Game Theory is the study of how players should rationally play games. We conclude by saying that the formulation of strategy, for example, at the national security level and the rational and logical playing of games are similar concepts.

Note that although strategists make a distinction between grand strategy, strategy and tactics, Game Theory makes no distinction between policy and lower order ends. It treats tactics and strategy exactly the same. However, we will concentrate on strategy appertaining to the generals and the politicians or, in other words, strategy relating to the national military and security levels. 


\section{GAME THEORY}

Various views exist as to the assumptions underlying Game Theory. However, we shall deal with only one such a school of thought. Heap and Varoufakis [5] hold that the following three broad assumptions underlie Game Theory:

- Individual action is instrumentally rational.

- There is a common knowledge of rationality and a consistent alignment of beliefs.

- Individual players know the rules of the game and a player's motive for choosing a particular action is strictly independent from the rules of the game.

Furthermore, Game Theory assumes that there is a finite set of players. These players may be people, groups of people, abstract entities or some coalition of forces. During the playing of a game, a player may be required to make one or more decisions in order to implement his strategy. For example, a player must decide on whether the outcome of the spinning of a coin would result in heads or tails; or in playing the game of noughts and crosses, the nought player must decide where to place the next nought every time after the cross player has placed a cross on the playing area. Thus, we define a strategy as the game plan for achieving a particular outcome.

We know that there might be several strategies available to a player and that he may play any of the strategies available to him with a certain probability. We denote these probabilities for their corresponding strategies, $i=1,2, \ldots, n$ by the strategy probability vector

$$
x=\left[\begin{array}{c}
x_{1} \\
x_{2} \\
\vdots \\
x_{m}
\end{array}\right]
$$

If a game is played repeatedly and a player plays the same strategy in all the repetitions of the game, that is, the strategy vector is such that one of its elements is one whilst the others are zero, the player is said to have a pure strategy. For example, if

$$
\left[\begin{array}{l}
x_{1} \\
x_{2}
\end{array}\right]=\left[\begin{array}{l}
1 \\
0
\end{array}\right]
$$

then the probability that the row player will play his first strategy is 1 and therefore he has a pure strategy. On the other hand, suppose the row player plays the available strategies in every iteration of the game with probabilities 


$$
\left[\begin{array}{l}
x_{1} \\
x_{2}
\end{array}\right]=\left[\begin{array}{l}
0.25 \\
0.75
\end{array}\right]
$$

then the row player is said to have a mixed strategy. Note that a mixed strategy for a player is a probability density distribution on the set of his pure strategies. In the case where the player has only a finite number of pure strategies, $m$, a mixed strategy reduces to a $m$-vector, $x=\left(x_{1}, x_{2}, \ldots, x_{m}\right)$ satisfying

$$
x_{i} \geq 0, i=1,2, \ldots, m
$$

and

$$
\sum_{i=1}^{m} x_{i}=1
$$

on completion of a game, each player receives a numerical pay-off that depends on his and his opponent's respective strategies. The pay-off might be negative, in which case it is interpreted as a loss to the player. Suppose we have a game with two players, each with two strategies, $x$ and $y$ respectively, then the outcomes for the two players of the game can be written in the $2 \mathrm{x}$ 2 bimatrix

$$
M(x, y)=(A, B)=\left[\begin{array}{ll}
\left(a_{11}, b_{11}\right) & \left(a_{12}, b_{12}\right) \\
\left(a_{21}, b_{21}\right) & \left(a_{22}, b_{22}\right)
\end{array}\right]
$$

where $A$ denotes the pay-offs for the player associated with the strategy probability vector $x$ and $B$ denotes the pay-off for the player associated with the strategy probability vector $y$. We often refer to a strategy probability vector as a strategy and to the player associated with the strategy $x$ as the row-player and to the player associated with the strategy $y$ as the columnplayer. This representation of a game is known as a game in normal form $[8,4-6]$.

Let us consider (5) in more detail. For any set of strategies there will be a pay-off to the row and column players respectively. Suppose that both have played their first strategies only, then the pay-off to them would be $a_{11}$ and $b_{11}$ respectively. If they both chooses strategies so as to optimise their pay-offs simultaneously, then we say that they are playing their optimal strategies. Furthermore, in the case of zero-sum games, that is games where $a_{i j}=$ $-b_{i j}$ the minimax theorem vouches for the fact that optimal strategies exist. Also, if the players have played mixed strategies, we can prove that the value of the game to the row-player, $v_{r}$, is equal to the value of the game to the column-player. Therefore, we define the value of the game by $v=v_{r}=v_{c}$.

Where optimal strategies do not exist for a game, and under certain particular circumstances only, we may find that $\varepsilon$-optimal strategies exist. A $\varepsilon$-optimal strategy is a strategy that can be considered a near-optimal strategy and where $\varepsilon$ is a measure of how near 
the strategy is to optimality. Note that Owen $[8,68]$ gives a more formal definition of $\varepsilon$ optimal strategies.

\section{NONZERO-SUM GAMES OF A NON CO-OPERATIVE NATURE}

\section{Two-Person Games}

Consider the Cold War. Kapp [7,106-120] makes the point that it is a complex history to analyse. This point is well taken. However, it is suggested that we could gain insight by focusing on a part of the problem only. In this section, we analyse the question whether to arm with nuclear weapons or not.

On one side was the United States (USA) with its NATO allies and on the other was the Union of Socialist Soviet Republics (USSR) and the Warschau Pact. These alliances formed after the Second World War and from the start they both pursued strategies of arming themselves to react in case of a war. In general, both sides depended heavily on nuclear arms.

For the sake of simplicity, we shall refer to the two opposing camps as the USA and the USSR respectively. Also, for our argument, we assume that the USA has a free enterprise national value which they wish to protect against the USSR's national value of communist imperialism and vice-versa. Now, suppose the USA pursues a strategy of nuclear armament and the USSR does not. If war between the two sides ensues, then the USA, assuming that it will use nuclear arms in a war against the USSR, will win such a war. This would lead to greater protection for the USA's free enterprise model and the probable demise of communist imperialism in the USSR. In this case we assign an arbitrary pay-off to the USA of 10 and an arbitrary pay-off to the USSR of zero. By this we mean that the USA, by winning the war, gains most and the USSR, by losing the war, gains little.

Likewise, should the USSR pursue a strategy of nuclear armament and the USA does not, the USSR would win an ensuing war by using nuclear weapons whilst the USA would lose the war. In turn, this would result in the demise of the free enterprise model in the USA and the establishment of communist imperialism in the USA. This, in turn, would lead to a pay-off assignment of 10 to the USSR and zero to the USA. Thus, the USSR gains by winning the war whilst the USA, by losing, gains nothing.

Now, if both sides decide on a strategy of nuclear armament and a war between them ensues, both sides stand to lose. Furthermore, we can assume a war of much higher intensity and as a result, both would lose substantially. Thus we assign an arbitrary pay-off of -5 to both sides. Also, if both sides decide not to arm themselves with nuclear weapons and we assume that, as a result, a war does not occur, then no side won outright, that is, neither the free enterprise model nor the communist imperialistic cause gained anything but both countries were spared the ordeal of war, then we assign an arbitrary pay-off of 5 to both.

If we assign the USA to be the row player and we assign the USSR to be the column player, then we can represent the four situations in the bimatrix 
Scientia Militaria, South African Journal of Military Studies, Vol 29, 1999. http://scientiamilitaria.journals.ac.za

$$
M(x, y)=\left[\begin{array}{cc}
(5,5) & (0,10) \\
(10,0) & (-5,-5)
\end{array}\right]
$$

Note that both players are obliged to have pure strategies in (6). It is a single move game where both players can decide on a strategy to arm themselves with nuclear weapons or not.

Furthermore, in any matrix $M(x, y)$, we say that the $i$ th row dominates the $k$ th row if

$$
a_{i j} \geq a_{k j} \text { for all } j
$$

and

$$
a_{i j}>a_{k j} \text { for at least one } j \text {. }
$$

Likewise, we say the $j$ th column dominates the $l$ th column if

$$
b_{i j} \leq b_{i l} \text { for all } i
$$

and

$$
b_{i j}<b_{i l} \text { for at least one } i \text {. }
$$

Now, it is easy to see that in (6) the second row dominates the first row and the second column dominates the first column. Therefore, the only equilibrium pair, (the bimatrix entry in any $M(x, y)$ such that none of the two players have any positive reason for changing their strategy) in (6) is given by the second pure strategy for both players. This would result in a pay-off of -5 to both players. However, should both players play the wrong strategy it would result in a much better pay-off of 5 to both players.

Let us consider this apparent contradiction. If both players decide to cooperate and as a result, none of them arm themselves with nuclear weapons, both can achieve the better pay-off of 5. However, should the USSR embark on the first pure strategy, the USA might double-cross him by playing his second pure strategy, that is, to arm himself with nuclear weapons, this would result in an outcome of zero to the USSR and the much better outcome of 10 to the USA. Thus, if both players agree to co-operate, they leave themselves open to a double-cross situation. In the absence of mutual trust, the game puts pressure on both players to become non-cooperative in choosing their strategies.

In this manner the scene is set for an arms race in terms of nuclear weapons. History bears testimony to this phenomenon. This type of game is known as the Prisoner's Dilemma $[2,52]$ and it explains to some degree why the USA and the USSR became prisoners of their nuclear arms race dilemma after the Second World War. However, the disintegration of communism removed an important Russian national value and made mutual trust possible to a larger degree. In turn, this has led to a significant reduction in nuclear weapons by both sides. 
The fact that the Cold War never turned into a full-scale global war, can be attributed by a large degree to the fact that both players were intensely aware of the negative pay-offs of their strategies. Kapp [7,119] states that the Cold War could be considered sui generis and, as a result, it has certain unique characteristics which, inter alia, included the presence of an ever escalating arsenal of nuclear arms. From a Game Theory perspective, we see the rationale for this characteristic.

\section{N-Person Games}

In order to illustrate the concept of the prisoner's dilemma for $n$-person games, let us suppose that a third country, China, was in a position to build nuclear weapons shortly after the secession of hostilities at the end of the Second World War and at the same time decided not to side with the USA or the USSR. Assume that a future war would be between two of the players only. Our game would now have three players, each with two pure strategies to choose from and three pay-off bimatrices, $(A, B),(A, C)$ and $(B, C)$ which would have looked very similar. It is proposed that the problem of mutual trust would have been much bigger and the forces for non-cooperation, much larger. Even with the demise of communism in Russia, no arms limitation would have been possible. Because of the Chinese version of communist imperialistic values and the theoretical nuclear arms level still remaining in China, the other two players would still have been locked into the nuclear arms race.

If we consider the case where a future war will be between all three parties simultaneously and the first pure strategy would be not to arm, whilst the second pure strategy is to arm, the three pay-off bimatrices can be written in a $2 \times 2 \times 2$ trimatrix $M(x, y, z)$. With the pay-offs based on the $2 \times 2$ game we find that

$$
M\left(x, y, z_{1}\right)=\left(A, B, z_{1}\right)=\left[\begin{array}{cc}
(5,5,5) & (0,10,0) \\
(10,0,0) & (-5,-5,0)
\end{array}\right]
$$

and

$$
M\left(x, y, z_{2}\right)=\left(A, B, z_{2}\right)=\left[\begin{array}{cc}
(0,0,10) & (0,-5,-5) \\
(-5,0,-5) & (-5,-5,-5)
\end{array}\right]
$$

where $z_{k}$ denotes China's chosen strategy and $k=1.2$.

If we consider (7) only, that is, the USA and USSR can play any strategy whilst China plays only the first strategy then we intuitively see that the outcomes for both the USA and the USSR do not change. However, if we consider (8), that is, China plays its second strategy only, the situation changes drastically. For example, if the USSR decides not to arm, whilst the USA and China decide to arm, then the pay-off to the three players $m_{212}=(-5,0,-5)$. We explain this outcome by saying that the war between the two parties that possess nuclear arms will be more intense than the war between them and the party that does not possess nuclear arms. The two parties possessing nuclear arms will sustain more 
damage with the resultant -5 pay-offs. The party that does not possess nuclear arms might loose the war but will sustain less damage and thus an outcome of zero will result.

We have made these findings by inspection of (7) and (8). However, it is more difficult to find dominant strategies for the individual players. As a result, it is more difficult to find an equilibrium 3-tuple. Intuitively we assume that such an equilibrium 3-tuple might not exist. If we expand this game to games where $N>3$ the problem might become much worse.

\section{Conclusions in regard to the Prisoner's Dilemma}

We have shown how the $2 \times 2$ Prisoner's Dilemma investigates and explains why the USA and the USSR were both bent on a strategy of arming themselves with nuclear weapons. By adding another player to the game and assuming that an eventual war would be between two parties only, we have predicted that the resultant non-cooperative strategies would persist. If we assume a more global war, that is, all three parties take part in such a war without any coalition forming, we predict that the outcomes to all the parties might worsen. Furthermore, there is some evidence to prescribe a strategy of not arming with nuclear weapons.

\section{RECURSIVE GAMES}

\section{Definition}

A recursive game is a repeated game in which pay-offs are made only at the termination of the game. Furthermore, at any stage, the game could be terminated or it could be continued whilst the probability of termination at any stage might be zero.

\section{Scenario}

We assume that the following two hypotheses are true:

- A state's national values together with its available resources defines its power base explicitly. In turn, the state's power base acts as an enabler for its national values.

- The national interests of a state are aimed at protecting its power base and as a result, its national values.

\section{Strategic Ends}

Suppose there exist two states, Andersland and Bothnia respectively. The two states have national values such that their respective economic power-bases are threatened by one another. Both states decide on a national security strategy that warrants a war between the two countries. It suffices to say, the nature of this war is to attack the other by military means and the required end is the destruction of the other's military power base. 


\section{Strategic Means}

Furthermore, suppose Andersland has three units of military power and Bothnia has only two units of military power. We assume that military force can only be applied in full units of military power. Therefore, we will express forces in terms of units of military power. Andersland's military objective is to take Bothnia's rear area without losing his own rear area. In turn, Bothnia's military objective is to take Andersland's rear area without loosing his own rear area. The present situation is that both state's military forces are assembled in their own rear areas.

\section{Strategic Ways}

However, Andersland must be careful. If it attacks Bothnia's rear area Bothnia might simultaneously manoeuvre adversely and attack Andersland's rear area. The military assumes that an attacker must have a superiority of forces equal to one unit of military power to reach its military objective. If the attacking force is not large enough, it must simply retreat to its own rear area and the war will recommence at the following state.

\section{The Recursive Game}

The pay-off is +1 if Andersland reaches its military objective, that is, if Andersland takes Bothnia's rear area without losing his own rear area. Also, the pay-off is -1 if Bothnia reaches its military objective, that is, if Bothnia takes Andersland's rear area without losing his own rear area. The pay-off for indefinite play is zero. Everett [3] first formulated this type of recursive game named the Blotto games after the infamous protagonist Colonel Blotto.

The game can be represented by a single game element $\Gamma$. The strategies in $\Gamma$ correspond to a division of attacking and defending units. As a result, Andersland has four strategies, namely, attack with zero, one, two or three units of military power. Likewise, Bothnia has only three strategies, namely, attack with zero, one or two units of military power.

The matrix, $\Gamma_{l-1}$, for this game is

$$
\Gamma_{l-1}=\left[\begin{array}{rrr}
\Gamma_{l} & \Gamma_{l} & \Gamma_{l} \\
\Gamma_{l} & \Gamma_{l} & 1 \\
\Gamma_{l} & 1 & -1 \\
1 & -1 & -1
\end{array}\right]
$$

Note that $\Gamma_{l-1}$ is exactly the same game as $\Gamma_{l}$ but $\Gamma_{l}$ is played at the stage after the stage at which $\Gamma_{l-1}$ is played. It can be shown that the value of the game for the row player is +1 . 


\section{Optimal Strategies}

Furthermore, it can be shown that there are no optimal strategies for this game. However, because we can calculate a value for the row player's game an $\varepsilon$-optimal strategy (row player's near optimal strategy under these circumstances only) for Andersland does exist and it is of the form

$$
\left(0,1-\delta-\delta^{2}, \delta, \delta^{2}\right)
$$

where $\delta$ is such that $0 \leq \delta+\delta^{2} \leq 1[8,103]$.

Note that as $\delta$ tends to zero, the probability that Andersland achieves its military objective becomes larger; but the longer the expected length of play will be. Therefore, a patient approach by Andersland will pay off in the long run.

However, if we let $\delta=0$, then the game might be repeated indefinitely, that is, the war will never end. Therefore, an optimal strategy for Andersland does not exists.

\section{Conclusions in regard to the Blotto Game}

This example bears out Dunningan [1] when he says that; "All things being equal, defending is easier than attacking". In this model we have shown how Game Theory explains how a strategy based on superiority of force alone might develop. Also, it would be interesting to investigate whether analysis of the Somme Campaign during the First World War and the march on the Netherlands and North-East Germany by Montgomery during the Second World War could reveal some of the properties associated with Colonel Blotto games.

\section{GAMES OF EXHAUSTION}

\section{The Inspection Game}

The inspection game is a game of exhaustion that prescribes a particular strategy $[8,93]$. Suppose a certain navy has a duty to apprehend a fisherman that transgresses certain fishing regulations. The navy decides on a strategy of random patrols to achieve their objective which is to maximise the probability that they would apprehend him when he transgresses the fishing regulations. However, the navy, due to financial constraints, can carry out only one patrol in every $N$ time periods. In theses $N$ time periods the transgressor can commit a single illegal act. We denote the transgressor as Player 1 and the navy as Player 2. Furthermore, the pay-off for the game, $\Gamma_{N}$ is +1 if the illegal action remains undetected and -1 if the transgressor is caught.

In the first stage of the game, that is the first time period, each player must decide on one of the following two strategies: 
- Player 1 can transgress the fishing regulations or not. Thus he can decide to act or not to act.

- Player 2 can patrol or not patrol. For our purposes we say that he can decide to inspect or not inspect.

As a result, we have the following scenarios:

- If Player 1 acts and Player 2 inspects, then the game is over and the pay-off is -1 . By this we mean that the transgressor is caught by the navy.

- If Player 1 acts and Player 2 does not inspect, then the game is over and the payoff is +1 . Note that the navy may decide to patrol later, but the transgressor has already committed his act and cannot be caught.

- If Player 1 does not act and Player 2 inspects, then Player 1, assuming $N>1$, could act at any subsequent stage and therefore the game is considered over and the payoff is +1 .

- If Player 1 does not act and Player 2 does not inspect, then the game moves to the next stage where both players are obliged to play the game again and we have $N$ -1 time periods left.

The resultant pay-off matrix for the time period is

$$
\Gamma_{N}=\left[\begin{array}{cc}
-1 & 1 \\
1 & \Gamma_{N-1}
\end{array}\right]
$$

which results in the recursive definition of the value of the game being

$$
v_{N}=\operatorname{val}\left[\begin{array}{cc}
-1 & 1 \\
1 & \Gamma_{N-1}
\end{array}\right]
$$

where the term val denotes the value of the $N$ th game. We note that $v_{N-1}<1$ and as a result the game does not have a saddle point. That means that there are no explicit optimal pure strategies for the players. In such a case, the value of the game is given by

$$
v=\frac{|A|}{J A^{*} J^{\mathrm{T}}}
$$

where $|A|$ is the determinant of the matrix $A, A^{*}$ is the adjoint of the matrix $A$ and $J^{\mathrm{T}}$ is the matrix [ $\left[\begin{array}{ll}1 & 1\end{array}\right]$. When we apply this equation to the game, we find the difference equation 
Scientia Militaria, South African Journal of Military Studies, Vol 29, 1999. http://scientiamilitaria.journals.ac.za

$$
v_{N}=\frac{v_{N-1}+1}{-v_{N-1}+3}
$$

which, with the initial condition $v_{1}=0$, defines $v_{N}$. By using the substitution

$$
t_{N}=\frac{1}{v_{N}-1}
$$

we solve for $v_{N}$ and we find the new difference equation

$$
t_{N}=t_{N-1}-\frac{1}{2}
$$

and

$$
t_{1}=-1 .
$$

It is easy to show by mathematical induction that the equation has the obvious solution

$$
t_{N}=-\frac{N+1}{2}
$$

and in turn, results in

$$
v_{N}=\frac{N-1}{N+1} .
$$

Therefore this new definition of $v_{N}$ gives us the value of the game at each stage and the game matrix now becomes

$$
\left[\begin{array}{cc}
-1 & 1 \\
1 & \frac{N-2}{N}
\end{array}\right]
$$

and the optimal strategies for $N \geq 2$ are

$$
x=\left[\frac{1}{N+1}, \frac{N}{N+1}\right]
$$

and

$$
y=\left[\frac{1}{N+1}, \frac{N}{N+1}\right]
$$

where $x$ is the optimal strategy for the Player 1 and $y$ is the optimal strategy for Player 2. 


\section{Interpretation of the Results}

Suppose that, in our example, the navy can patrol the defined area once in every eight time periods, then, from (18), the value of the game is $\frac{7}{9}$ whilst the optimal mixed strategies from (20) and $(21)$ are $x=\left(\frac{1}{9}, \frac{8}{9}\right)$ and $y=\left(\frac{1}{9}, \frac{8}{9}\right)$ respectively for at least two time periods remaining. We prescribe the optimal strategy for the navy to be the following:

The navy, at the beginning of any time period decides with a probability of $\frac{1}{9}$ to patrol the area and with a probability of $\frac{8}{9}$ not to patrol the area.

Furthermore, the optimal strategy for the transgressing fisherman is the following:

The fisherman, at the beginning of any time period decides with a probability of $\frac{1}{9}$ to transgress the fishing regulations in the area and with a probability of $\frac{8}{9}$ not to transgress the fishing regulations of the area.

The value of the game is such that the fisherman would get away with his transgression for at least seven out of every nine transgressions. However, if he does not play his optimal strategy, the navy's probability of apprehending him will increase to above $\frac{2}{9}$. If he plays his optimal strategy, the navy's probability of apprehending him will never increase above $\frac{2}{9}$. However, should the navy not follow its optimal strategy, the probability of apprehending the transgressing fisherman will reduce accordingly.

\section{Higher Level Strategies}

The inspection game can be applied to higher level strategies. Suppose it is of national security importance that the South African government is aware of the fact that a ship carrying nuclear waste is using the Cape sea route, but the flying of maritime patrols is curtailed by financial constraints. Patrols of a duration of twelve hours can only be flown once in twelve days. Also, suppose it will take such a ship four days to round the Cape of Good Hope. This translates into an inspection game where $N=3$ with the resultant

$$
\begin{aligned}
& v=\frac{1}{2}, \\
& x=\left[\frac{1}{4}, \frac{3}{4}\right], \\
& y=\left[\frac{1}{4}, \frac{3}{4}\right] .
\end{aligned}
$$

If maritime air patrols are ordered in accordance with this strategy and the fact that the ship carrying nuclear waste is not likely to follow its optimal strategy, the South African 
government should know, with probability of larger than $50 \%$, whether ships carrying nuclear waste is on its seaboard.

\section{Conclusions in regard to the Inspection Game}

The inspection game enables us to derive optimal strategies for this particular scenario. Therefore, we are able to prescribe an optimal strategy and predict the minimum probability that such a strategy will be successful. Likewise, we can prescribe and predict the outcome of any strategy that can be modelled as an inspection game.

\section{$N$-PERSON GAMES}

No general existence theorem has been given to date for $n$-person games $[8,261]$. This has led many mathematicians to look for alternative solution concepts. One such mathematician, L.S. Shapley[9] first published such an alternative concept in 1953. This concept became known as the Shapley value, $\varphi$. The Shapley value quantifies the amount of power that resides in each of the $N$ players in the game.

\section{Problem Statement}

It is often in the national interest of a state to form coalitions with other states. Such states are normally equal partners in the coalition although their contributions might not be equal in nature. For example, in a coalition between Mozambique and South Africa in order to protect the national security of both states, Mozambique, at present, might not be able to provide as much as South Africa. To be equal partners in such a coalition might be considered unfair by many South Africans.

Likewise, the NATO alliance consists of many states that can only contribute to NATO to a varying degree. The USA is by far the major contributor in terms of hardware and troops whereas Poland, who is about to join NATO, can contribute relatively little. Again, is it fair to the USA that Poland would have an equal say in NATO? Indeed, that is not the case. NATO's individual membership has a certain amount of power that is more or less in line with their contributions to the alliance. Furthermore, suppose that such an alliance allows a number of votes proportional to individual members that is equal to the individual's contribution to the alliance. Will that result in a distribution of power within the alliance that is congruent to the number of votes that each member might have? Furthermore, how would coalition forming within the alliance skew the balance of power in that alliance?

\section{The Shapley Value}

By way of an example, let an alliance consist of four states such that the first state contributes 10 units, the second state contributes 20 units, the third state contributes 30 units and the fourth state contributes 40 units. Let a state have the number of votes within the alliance proportional to its contribution. Furthermore, we assume that any decision can be settled by a simple majority vote. This situation can be treated as a simple 4-person game in 
which the winning coalitions are $\{2,4\},\{3,4\},\{1,2,3\},\{1,2,4\},\{1,3,4\},\{2,3,4\}$ and $\{1$, $2,3,4\}$ where the four states are denoted $1,2,3$ and 4 respectively.

The Shapley values are written in vector format and for this particular game where $n$ $=4$ players, the Shapley value is the vector

$$
\varphi=\left(\varphi_{1}, \varphi_{2}, \varphi_{3}, \varphi_{4}\right)
$$

To find $\varphi_{1}$ we note that the only winning coalition $T$ such that $T-\{1\}$ is not a winning coalition, is the coalition $\{1,2,3\}$. As there are three players in $T$, we set the number of players in $T$ to $t=3$. Thus, according to Owen $[8,265]$, we find

$$
\begin{aligned}
\varphi_{1} & =\frac{(t-1) !(n-t) !}{n !}[1] \\
& =\frac{(3-1) !(4-3) !}{4 !} \\
& =\frac{2 ! 1 !}{4 !} \\
& =\frac{1}{12} .
\end{aligned}
$$

Likewise, to find $\varphi_{2}$ we note that $\{2,4\},\{1,2,3\}$ and $\{2,3,4\}$ are the only winning coalitions which will not win for $T-\{2\}$. By the same method, we find that

$$
\begin{gathered}
\varphi_{2}=\frac{1}{12}+\frac{1}{12}+\frac{1}{12} \\
=\frac{1}{4}, \\
\varphi_{3}=\frac{1}{4}
\end{gathered}
$$

and

$$
\varphi_{4}=\frac{5}{12}
$$

Therefore, the Shapley value for this game is

$$
\begin{aligned}
\varphi & =\left(\frac{1}{12}, \frac{1}{4}, \frac{1}{4}, \frac{5}{12}\right) \\
& \approx(0.08,0.25,0.25,0.42) .
\end{aligned}
$$




\section{Interpretation of the Shapley Value}

Remember that the four states have $0.1,0.2,0.3$ and 0.4 of the total vote respectively. We see that the state with the smallest contribution has less power within the alliance than what its proportion of votes would imply. The two states with 0.2 and 0.3 of the votes respectively have the same power through coalition forming whilst the stronger state's position in terms of power is enhanced. This reminds one somewhat of the passage in the Holy Bible [St Matthew 25:29] which reads, "For unto everyone that hath shall be given, and he shall hath abundance: but from him that hath not shall be taken away even that which he hath".

\section{Conclusions in regard to the Shapley Value}

We have shown that the Shapley value can be used to study power relations within groups and alliances and as a result, it investigates and explains to what extent a particular state or person has power within such groups or alliances. Furthermore, if states in an alliance decide on a particular power sharing model, the Shapley value can be used to find an equitable number of votes for all the members of the alliance. It can also aid individual members of an alliance to find a suitable strategy for minimising its contributions to the alliance in question but keeping its power within the alliance at a certain predetermined level. Thus, it can be prescriptive in nature.

\section{CONCLUSIONS}

We have shown how Game Theory can be used in varying degrees to predict or explain the outcome of a strategy, investigate the causes of a particular outcome to a strategy, describe a particular type of situation with its associated strategies and prescribe optimal strategies. We have used only some examples to illustrate the point. However, the list of standard games available to the strategist is extensive and a comprehensive knowledge of the subject is required to enable the full power of Game Theory.

Certain shortcomings in Game Theory are apparent. When we explored the possibility of a third party entering into a nonzero-sum game of a non-cooperative nature, we found that it became nearly impossible to find dominance within rows, columns and other dimensions of the then defined $n$-person game. Thus the existence of equilibrium $n$-tuples could not be established easily.

Despite these shortcomings in Game Theory, it is submitted that the subject is useful in so far as it aids in the understanding of strategy in terms of the prediction and explanation of outcomes, the describing and the prescription of strategy. Game Theory is part of the strategist's armour or toolbox containing today's scientific knowledge. Thus, the strategist is obliged to use it in order to ensure the formulation of quality strategies. In fact, the strategist who ignores Game Theory, does so at his own peril. 


\section{REFERENCES}

(1) Dunnigan, J.F., 1993. How to make War. 3 ed, New York: William Morrow.

(2) Engelbrecht G.N., 1997. Game Theory - A Mathematical Approach to Strategy. Centurion: Unpublished [Available at the Samual Pauw Library, Unisa].

(3) Everett, H., "Recursive Games", in: Contributions to the Theory of Games, Vol. III. (Annals of Mathematical Studies 39), edited by M. Dresher, A.W. Tucker and P. Wolfe, Princeton: Princeton University Press.

(4) Frontiers of Game Theory, edited by Binmore, K., Kirman, A. and Piero, T., 1993. Cambridge, Ma: MIT.

(5) Heap, S.P.H. and Varoufakis, Y., 1995. Game Theory - A Critical Introduction. London: Routledge.

(6) Heinl, Jr, R.D., 1966. Dictionary of Military and Naval Quotations. Annapolis: Naval Institute.

(7) Kapp, P.H., "The Cold War: The World's Longest War?", in: Scientiae Militaria, Vol 37, edited by G.E. Visser et. al. Saldanha: University of Stellenbosch, Faculty of Military Science.

(8) Owen, G., 1995. Game Theory. 3 ed. San Diego, Ca;: Academic Press.

(9) Shapley, L.S., 1953; "A Value for N-person Games", Contributions to the Theory of Games. Vol 2. Edited by H.W. Kuhn and A.W. Tucker. Princeton: Princeton University Press.

(10) Straffin, P.D., 1993. Game Theory and Strategy. New York: The Mathematical Association of America.

(11) Till, G., 1984. Maritime Strategy and the Nuclear Age. 2 ed. New York: St Martins.

(12) Von Clausewitz, C., [1832] 1968, On War. Edited with an introduction and notes by Anatol Repoport. Harmondsworth, England: Penguin Books. 